\title{
GCU
}

Glasgow Caledonian

University

University for the Common Good

\section{Assessment of environmental performance of shaped tube electrolytic machining (STEM) and capillary drilling (CD) of superalloys}

De Silva, Anjali K.M.; Gamage, Janaka R.; Harrison, Colin S.

Published in:

CIRP Annals: Manufacturing Technology

DOI:

10.1016/j.cirp.2017.04.110

Publication date:

2017

Document Version

Author accepted manuscript

Link to publication in ResearchOnline

Citation for published version (Harvard):

De Silva, AKM, Gamage, JR \& Harrison, CS 2017, 'Assessment of environmental performance of shaped tube electrolytic machining (STEM) and capillary drilling (CD) of superalloys', CIRP Annals: Manufacturing

Technology, vol. 66, no. 1, pp. 57-60. https://doi.org/10.1016/j.cirp.2017.04.110

\section{General rights}

Copyright and moral rights for the publications made accessible in the public portal are retained by the authors and/or other copyright owners and it is a condition of accessing publications that users recognise and abide by the legal requirements associated with these rights.

Take down policy

If you believe that this document breaches copyright please view our takedown policy at https://edshare.gcu.ac.uk/id/eprint/5179 for details

of how to contact us. 


\title{
Assessment of environmental performance of shaped tube electrolytic machining (STEM) and capillary drilling (CD) of superalloys
}

\author{
Anjali K. M. De Silva (2), Janaka R. Gamage, Colin S. Harrison \\ School of Engineering and Built Environment, Glasgow Caledonian University, Cowcaddens Road, Glasgow G4 OBA, United Kingdom
}

\begin{abstract}
This paper presents an environmental impact assessment of two specialised electrochemical machining processes, STEM and CD, which are used for making cooling holes in turbine blades for aerospace applications. An industry friendly data collection framework was developed taking insights from CO2PE! and ISO 14044:2006 for ascertaining unit process lifecycle inventories (UPLCI). The 'ReCiPe2008' LCA method was used to analyse the environmental impact from a holistic point of view, the contribution from each inventory item, and the impact at the endpoint level. An uncertainty analysis was also performed to assess and improve the credibility of the findings.
\end{abstract}

Electro chemical machining (ECM), Environmental damage, unit process life cyle inventory (UPLCI)

\section{Introduction}

Most manufacturing industry sectors today are striving for sustainable ways of operating in order to be globally compliant and competitive. The research on the environmental aspects of sustainability tends to focus on products/materials and their use phase rather than the manufacturing process phase[1]. Several collaborative initiatives, such as 'CO2PE' [2], have tried to address this shortcoming at process level data. Duflou et al [3] give a comprehensive review of the energy and resource efficiency studies from process to system level, while a structured overview of environmental impact reduction at unit process as well as multi-machine tool level for unconventional machining is given by Kellens et al [4]. Additive and subtractive processes have been compared with regard to their environmental impact using life cycle analysis (LCA) to define criteria for environmental tradeoffs [5]. Electrodischarge machining (EDM) has been investigated for unit process environmental performance by Gamage [6] and Kellens [7]. There is however a paucity of literature concerning electrochemical machining (ECM) environmental impact, with only an early CIRP keynote paper giving a brief overview of ECM emissions [8].

ECM, although not as widely used in industry as the similar process EDM, plays an important and niche role in industry, sometimes being the only viable option for manufacturing certain parts, for example, high aspect ratio precision hole drilling in hard to machine alloys. To this end, this paper focusses on the environmental impact study of two ECM techniques widely used in the aerospace industry: Shaped-Tube Electrolytic Machining (STEM) and Capillary Drilling (CD). STEM drilling is capable of cooling holes of $0.5 \mathrm{~mm}$ diameter, 300 aspect ratio in aero engine blades [9], and in CD typical aspect ratios up to 100:1 with hole diameters 0.13 to $0.9 \mathrm{~mm}$, with simultaneous multiple holes up to $150[10]$.

\section{Methodology}

This research is based on evaluating the main environmental stresses of ECM: energy; consumables and emissions for a given time period of ECM in an industrial operation. A data collection framework is developed to suit industrial settings, taking insights from IS014044:2006 and 'CO2PE!', which is a method for systematic life cycle inventory (LCI) analysis for the use phase of a manufacturing process. Fig. 1 shows the simplified data collection framework

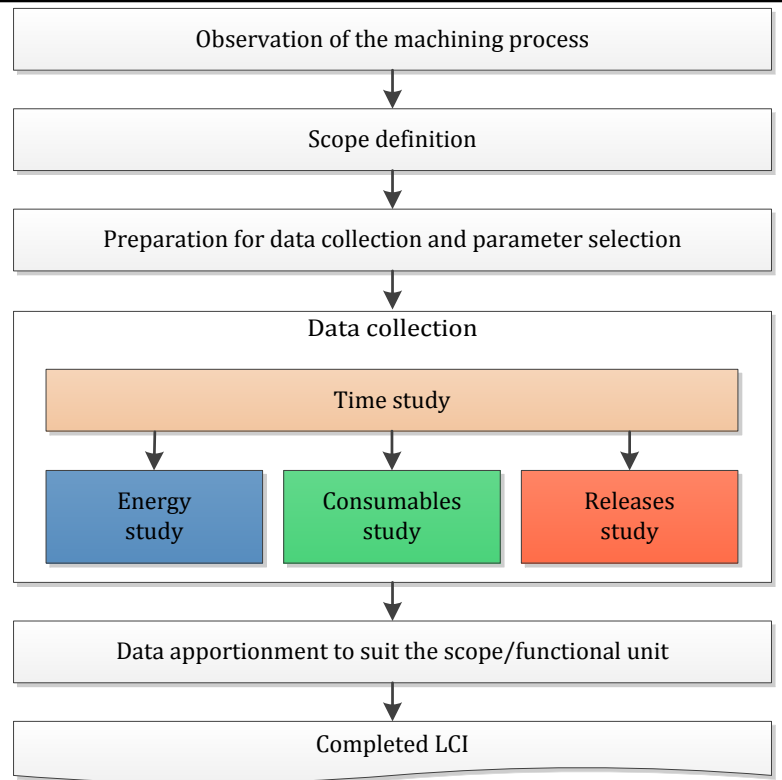

Fig. 1. Simplified data collection and analysis framework

After initial onsite observation of the machining process, the scope and system boundary were defined to identify appropriate forms of data. The measuring instruments and methods were then set up to capture the required data. Time study plays a key role in apportioning energy, consumables, and emissions for a given duration of machining. Energy consumption data were obtained using a data logger with a logging interval of one second. Clamping the logger around the supply power terminal of the machine enabled the integration of the total power consumption by all the subunits, assuming a balanced load on each phase with a 0.85 power factor and a $240 \mathrm{~V}$ line voltage.

The consumables study recorded the material input flow required to perform the machining job from start to finish. Consumables were traced by onsite observations and informal interviews of machine operators. For ECM, typical consumables are the electrolyte, filter materials, and water.

Emissions data captured were limited to solids and liquids as measuring gaseous emissions was not practicable in the industry setting since it needed a dedicated enclosure covering the entire machine to monitor inlet and outlet air.

Among many life cycle analysis (LCA) methods, 'ReCipe2008' was chosen as it offers a common platform to both midpoint and 
endpoint based methods [11]. 'Ecoinvent' (version3.3) LCI database [12] is used for the impact assessment. The 'SimaPro8' LCA software has been used for the analysis. ReCiPe single score method presents the absolute impact figure in 'ecopoints'. An ecopoints score (Pt) is calculated considering the average annual environmental impact/load of a European citizen in the year 2000 as the base value.

\section{Case studies}

STEM and CD machining processes were monitored onsite for five days of 24 hours operation.

\subsection{STEM}

The study was based on a STEM machine (TEK4 - eSTEM $®$ ) drilling cooling holes of varying diameters in aero turbine blades (Inconel 738).

Figure 2 shows the basic STEM drilling arrangement. The shaped tubes (coated titanium) also referred to as stems, are the cathode tools. Electrolyte (Nitric acid - 20\% v/v) is pumped through the tubes to the machining gap. During machining, fresh electrolyte is pumped continuously to each of the four stations at required pressure levels. The used electrolyte is circulated through a plate-type heat exchanger for cooling and two types of filters before the tank, the temperature of which is maintained at $18^{\circ} \mathrm{C}$. The electrolyte is recirculated until 6-blades are done and then replaced during a full machine reset. A bi-polar power supply (up to $20 \mathrm{~V}-1000 \mathrm{~A}$ ) capable of reversing polarity for few milliseconds to prevent tool build-up is used for STEM .

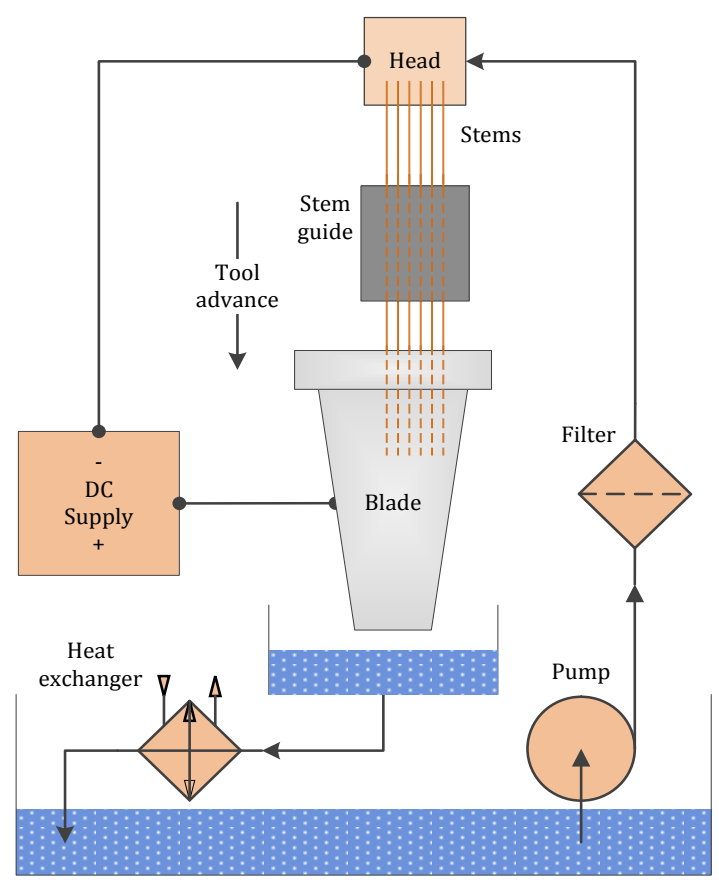

Fig. 2. Basic STEM drilling arrangement

Twelve holes per blade were drilled using the four stations in four successive passes, both from root and tip, joining in the middle. The hole diameters at the blade tip varied from 0.90 to $1.65 \mathrm{~mm}$, and at the root from 1.40 to $2.00 \mathrm{~mm}$ and the total depth $360 \mathrm{~mm}$.

Machining parameters for STEM are presented in Table 1. These settings are for a typical turbine blade type frequently processed by the company for its clients. Industry averages for each setting of STEM drilling are presented in the rightmost column in order to normalise the influence of parameters on the final results.
Table 1

Machining parameters - STEM

\begin{tabular}{llll}
\hline Parameter & Programmed setting & Industry averages [10] \\
\hline Forward voltage $\left(\mathrm{V}_{\mathrm{f}}\right)$ & $17.0 \mathrm{~V}$ & $5-15 \mathrm{~V}$ \\
Forward time $\left(\mathrm{t}_{\mathrm{f}}\right)$ & $6.00 \mathrm{~s}$ & N/A \\
Reverse voltage $\left(\mathrm{V}_{\mathrm{r}}\right)$ & $1.5 \mathrm{~V}$ & N/A \\
Reverse time $\left(\mathrm{t}_{\mathrm{r}}\right)$ & $0.15 \mathrm{~s}$ & N/A \\
Feed rate & $1.9 \mathrm{~mm} / \mathrm{min}$ & $1-3.5 \mathrm{~mm} / \mathrm{min}$ \\
Pressure $(\mathrm{STEM}$ head) & $3.5 \mathrm{bar}$ & $3-10 \mathrm{bar}(43-145 \mathrm{psi})$ \\
Electrolyte temperature & $18-22^{\circ} \mathrm{C}$ & N/A \\
\hline
\end{tabular}

\subsection{Capillary drilling}

Drilling micro cooling holes (regular holes of $0.051 \mathrm{~mm}$ diameter and $8.80 \mathrm{~mm}$ depth) in the trailing edge of another aerospace turbine blade (aluminium alloy 7150) was undertaken. One tool head comprises 23 glass capillaries with platinum electrodes. Drilling is done in three successive passes to complete 69 holes in each blade. Two blades are drilled simultaneously.

Figure 3 shows the basic capillary drilling arrangement, where fresh electrolyte is pumped through a stainless steel mesh type filter to the electrode head or magazine. The used electrolyte is pumped back to the storage tank through a polypropylene woven type filter.

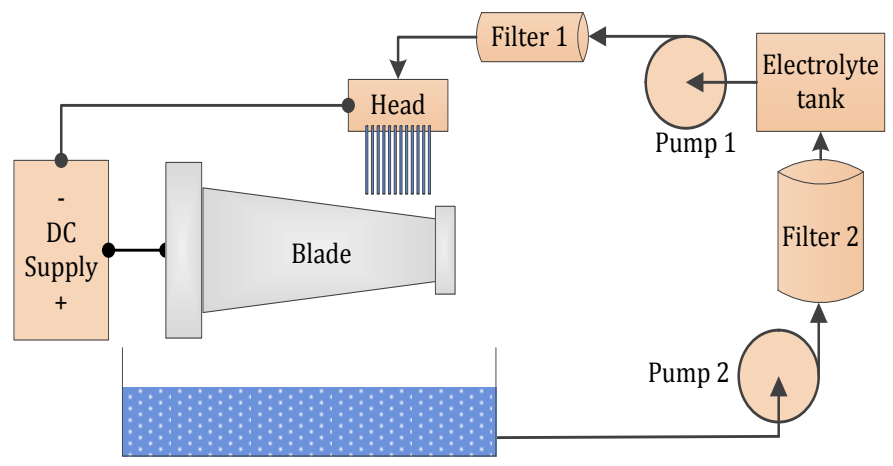

Fig. 3. Basic capillary drilling arrangement

Error! Not a valid bookmark self-reference. shows the machining parameters for $\mathrm{CD}$ with industry average setting listed in the right most column.

Table 2

Machining parameters - Capillary drilling

\begin{tabular}{lll}
\hline Parameter & Programmed setting & Industry averages[10] \\
\hline Voltage $(\mathrm{dc})$ & $\approx 83 \mathrm{~V}$ & $100-200 \mathrm{~V}$ \\
Feed rate & $1.8 \mathrm{~mm} / \mathrm{min}$ & $1-4 \mathrm{~mm} / \mathrm{min}$ \\
Electrolyte pressure at tool & $\mathrm{N} / \mathrm{A}$ & $3-20 \mathrm{bar}$ \\
Electrolyte temperature & $18-22^{\circ} \mathrm{C}$ & $\mathrm{N} / \mathrm{A}$ \\
\hline
\end{tabular}

\section{Analysis of results}

\subsection{Process energy performance}

In the time study, machining and non-machining times were ascertained to be $63 \%$ and $37 \%$, for STEM and $66 \%$ and $34 \%$ for CD. Non-machining activities refer to setting up, standby and waiting times. Total time to complete one blade was 112.3 minutes and 16.6 minutes for STEM and CD respectively. As expected, cycle times were shorter for CD than STEM, considering the depth and complexity of the shaped holes.

The energy study is also performed taking into account machining and non-machining energies. Figure 4 compares the energy consumption during one hour of processing. It can be seen 
that STEM consumes 2.6 times more energy (6.6 kWh) than CD, (2.56 kWh).

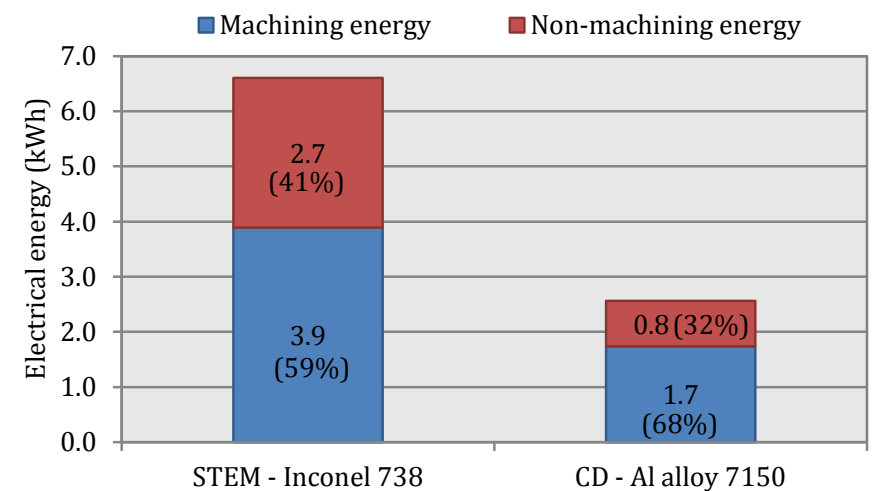

Fig. 4. Comparison of energy consumption during 1hour of machining

The amount of material removed by STEM is much higher than $\mathrm{CD}$ for a given time. Therefore, specific energy consumption (SEC) values were calculated in order to compare the energy performance of each type as plotted in Fig. . Two SEC values were calculated; SEC1 considering only the machining energy and SEC2, considering the total energy. The difference between SEC1 and SEC2 indicates the significance of non-machining energy per $\mathrm{mm}^{3}$ of material removed. It can be seen that the two SEC values appear closer to each other for STEM, but further apart for CD. In $\mathrm{CD}$, the additional energy of $13.3 \mathrm{~kJ}$ (SEC2-SEC1) per each $\mathrm{mm}^{3}$ of material removed can be attributed to non-machining energy. In general, it can be seen from Fig. that SEC with STEM is much lower compared to CD since the volume of removed material is higher for STEM. However, in the context of environmental performance, the absolute energy consumed is more relevant than the specific energy.

MRR was calculated by considering the total volume of material removed and time study results. Volume calculations of shaped holes in STEM were done using an x-ray of a drilled blade. The individual depths were measured for each hole as the tip and the root of the blades are not parallel and the diameters are different. It can be seen from Figure 5 that the MRR for STEM (128.7 $\mathrm{mm}^{3} / \mathrm{min}$ ) is 35 times higher compared to that of capillary drilling $3.7 \mathrm{~mm}^{3} / \mathrm{min}$.

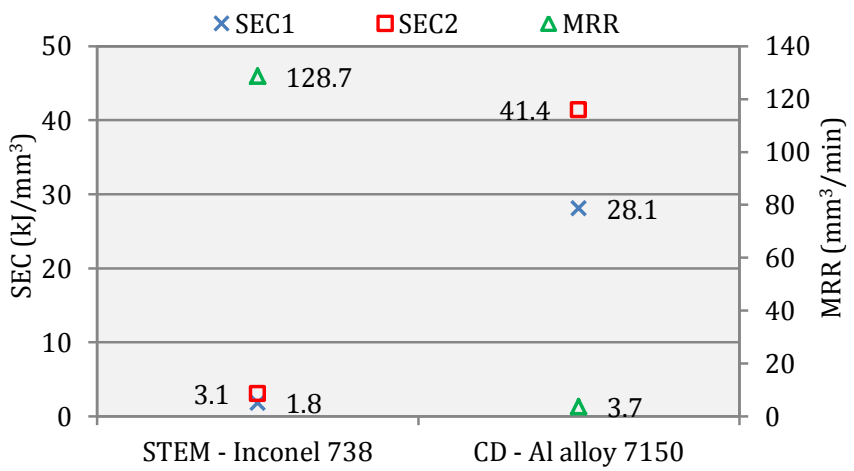

Fig. 5. Comparison of specific energy consumption and MRR

It should be noted that the workpiece material is different for each case and any influence from this is ignored.

\subsection{Environmental performance}

In order to apportion life cycle inventory an appropriate functional unit must be selected. The functional unit is referred to as 'quantified performance of a product system for use as a reference unit' [13]. Potential functional units for a machining process could be inventory per unit volume/weight of material removed, or to produce a part/geometry with certain dimensions [2]. However, as the two machining processes are not performing the same task and also the workpiece materials are not the same, the reference flows were allocated based on processing time. This enables the estimation of the absolute impact on the environment of each machining process; however with the limitation of comparison due to case specific parameters.

In order to capture sufficient amounts of reference flows, the process duration was set to one hour of machine operation, inclusive of supportive processes. The LCI data determined thus is presented in Table 3 and Table 4. The tables show the summary of machining cooling holes for 13 blades using STEM and 128 blades using CD over 5 days of onsite data collection. The tables show the quantities of consumables as observed entering and leaving the system boundary. For example, 500 litres of electrolyte replacement for every 6-blades were observed with STEM, and the used electrolyte is collected by the supplier itself. Therefore, access to any recycling data was not available and also out with the system boundary.

\section{Table 3}

Life cycle inventory of STEM drilling

\begin{tabular}{lll}
\hline & Inventory item & Amount/hour \\
\hline 1 & Electrical energy & $6.6 \mathrm{kWh}$ \\
2 & Electrolyte - $\mathrm{HNO}_{3} 20 \% \mathrm{v} / \mathrm{v}$ & $44.5 \mathrm{litres}$ \\
3 & Nickel(II) nitrate hexahydrate (additive for & 222.7 grams \\
& pH control of electrolyte) & 3.8 grams \\
4 & Bag filters - Polypropylene felt & 191.6 grams \\
5 & Woven filter cartridges Polypropylene & 71.3 millilitres \\
6 & Sodium Hydroxide (NaOH) - 20\% & 1.6 litres \\
7 & Water & 62.6 grams \\
8 & Work material - Inconel-738LC & \\
\hline
\end{tabular}

\section{Table 4}

Life cycle inventory of capillary drilling

\begin{tabular}{lll}
\hline & Inventory item & Amount/hour \\
\hline 1 & Electrical energy & $2.6 \mathrm{kWh}$ \\
2 & Electrolyte $-\mathrm{HNO}_{3} 20 \% \mathrm{v} / \mathrm{v}$ & $3.2 \mathrm{litres}$ \\
3 & Woven filter cartridges Polypropylene & 4.1 grams \\
4 & Work material - Al-alloy 7150 & $222.4 \mathrm{~mm}^{3}(0.63 \mathrm{~g})$ \\
\hline
\end{tabular}

Fig. illustrates the environmental impact for one hour of machining using the ReCiPe endpoint single score method. The primary axis shows the relative contribution of each inventory item and the secondary axis shows the absolute value of the total impact. It can be seen that the absolute impact of STEM $(6.01 \mathrm{Pt})$ is about 12 times more than that of capillary drilling $(0.51 \mathrm{Pt})$. The main contributor is the nitric acid electrolyte with $87 \%$ and $70 \%$ share in STEM and CD respectively. The total impact is almost equally shared by the electrolyte and the electrical energy in both cases as the other inventory items only showed marginal impact.

A Monte Carlo analysis was performed to account for data uncertainty by assigning a score for each inventory item using a pedigree matrix [14]. The matrix assessed data quality via five indicators: reliability, completeness, and temporal, geographical, and technological correlations. The error bars shown in the absolute impact columns (Figure 6) represent 95\% confidence level of the total impact values. A high confidence in the results is indicated as the error bars show variations less than $10 \%$. 


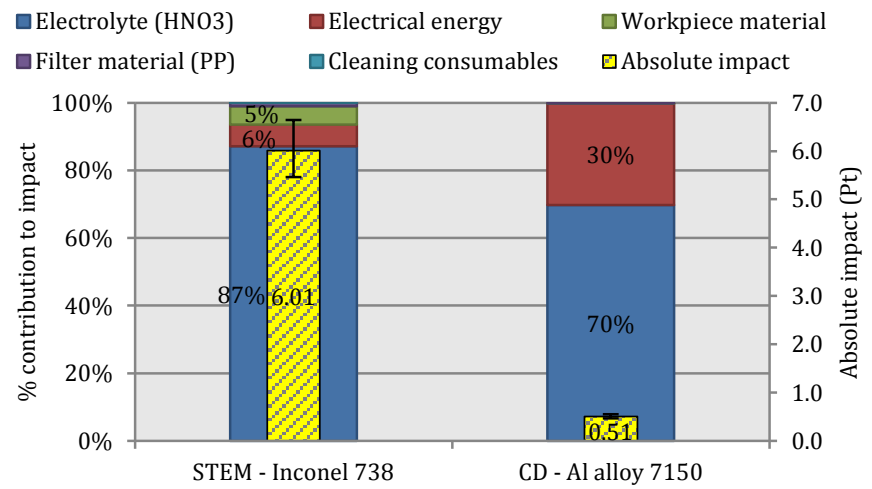

Fig. 6. Comparison of overall environmental performance

In order to consolidate the environmental impact of the two ECM processes, it is vital to analyse the impact at the endpoint of the environmental mechanism. ReCiPe considers three endpoint categories: damage to human health, damage to ecosystem diversity, and damage to resource availability. Fig. shows the relative impact on each damage category for STEM and CD. Although each endpoint category has its own units, the figure is formulated using single score values for ease of comparison

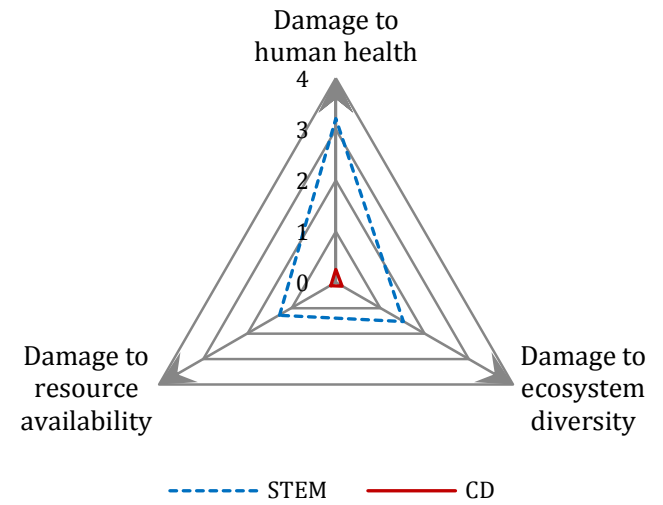

Fig. 7. Comparison of environmental performance at endpoint level

It can be seen from Figure 7 that both STEM and CD show highest to lowest impact on human health $(\mathrm{HH})$, ecosystems and resource availability categories respectively. STEM shows 12.7 times more impact on $\mathrm{HH}$ than that of $\mathrm{CD}$. Table 5 gives the corresponding units for each damage category. Damage to $\mathrm{HH}$ is measured using Disability Adjusted Life years (DALY), damage to ecosystems measured using Species-years, and resource availability using Dollars, which is the present value of marginal cost increases due to extraction of resources[11]. STEM shows higher impact values in the ecosystems and resource availability categories as well. This is 11.3 and 10.8 times compared to that of $\mathrm{CD}$, as can be seen in Table 5 .

Table 5

Comparison of impact at damage category level

\begin{tabular}{llll}
\hline Damage category & $\begin{array}{l}\text { STEM } \\
\text { Inconel-738 }\end{array}$ & $\begin{array}{l}\text { CD } \\
\text { Al-alloy 7150 }\end{array}$ & STEM/CD \\
\hline $\begin{array}{l}\text { Damage to Human health } \\
\text { (DALY) }\end{array}$ & $1.62 \times 10^{-4}$ & $1.28 \times 10^{-5}$ & 12.7 \\
$\begin{array}{l}\text { Damage to ecosystem } \\
\text { diversity (species.yr) }\end{array}$ & $6.89 \times 10^{-7}$ & $6.08 \times 10^{-8}$ & 11.3 \\
$\begin{array}{l}\text { Damage to resource } \\
\text { availability (US\$) }\end{array}$ & 1.97 & 0.18 & 10.8 \\
\hline
\end{tabular}

\section{Conclusions}

Environmental performance of two ECM unit processes, STEM and $\mathrm{CD}$, were evaluated at two levels: single score and endpoint. For one hour of processing time, the environmental impact of STEM is 12 times greater than that of capillary drilling. The largest impact is in the human health category due to the materials involved in processing cooling holes of turbine blades. Since different workpiece materials were used, the comparison of STEM with CD has some limitations. However, the influence of workpiece material was marginal compared to the influence of the electrolyte and electrical energy.

Further work by extending the scope of this research may help find the total blade production and thus estimating a full impact of an aerospace turbine. Another area for further research is to quantify ECM gaseous emissions and its heath implications.

\section{Acknowledgements}

Authors acknowledge the support of ELE Advanced Technologies Ltd for facilitating industrial data collection. Research studentship from Glasgow Caledonian University and funding for case study by RADMA association are also acknowledged.

\section{References}

[1] Helu, M., Vijayaraghavan, A., and Dornfeld, D., 2011, Evaluating the relationship between use phase environmental impacts and manufacturing process precision. CIRP Annals - Manufacturing Technology. 60 (1), 49-52.

[2] Kellens, K., Dewulf, W., Overcash, M., Hauschild, M.Z., and Duflou, J.R., 2011, Methodology for systematic analysis and improvement of manufacturing unit process life-cycle inventory (UPLCI) - CO2PE! initiative (cooperative effort on process emissions in manufacturing). Part 1: Methodology description. The International Journal of Life Cycle Assessment. 17 (1), 69-78.

[3] Duflou, J.R., Sutherland, J.W., Dornfeld, D., Herrmann, C., Jeswiet, J., Kara, S., et al. (2012) Towards energy and resource efficient manufacturing: A processes and systems approach. CIRP Annals - Manufacturing Technology. 61 (2), 587-609.

[4] Kellens, K., Dewulf, W., Lauwers, B., Kruth, J.-P., and Duflou, J.R., 2013, Environmental Impact Reduction in Discrete Manufacturing: Examples for NonConventional Processes. Procedia CIRP. 6 27-34.

[5] Paris, H., Mokhtarian, H., Coatanéa, E., Museau, M., and Ituarte, I.F., 2016, Comparative environmental impacts of additive and subtractive manufacturing technologies. CIRP Annals - Manufacturing Technology. 65 (1), 29-32.

[6] Gamage, J.R., DeSilva, A.K.M., Harrison, C.S., and Harrison, D.K., 2016, Process level environmental performance of electrodischarge machining of aluminium (3003) and steel (AISI P20). Journal of Cleaner Production.

[7] Kellens, K., Renaldi, Dewulf, W., and Duflou, J.R., 2011, Preliminary Environmental Assessment of Electrical Discharge Machining. in: J. Hesselbach, C. Herrmann (Eds.), Glocalized Solut. Sustain. Manuf., Springer Berlin Heidelberg, pp. 377-382.

[8] Tönshoff, H.K., Egger, R., and Klocke, F., 1996, Environmental and Safety Aspects of Electrophysical and Electrochemical Processes. CIRP Annals Manufacturing Technology. 45 (2), 553-568.

[9] Ali, S., Hinduja, S., Atkinson, J., and Pandya, M., 2009, Shaped tube electrochemical drilling of good quality holes. CIRP Annals - Manufacturing Technology. 58 (1), 185-188.

[10] Sen, M. and Shan, H.S., 2005, A review of electrochemical macro- to micro-hole drilling processes. International Journal of Machine Tools and Manufacture. 45 (2), 137-152.

[11] Goedkoop, M., Heijungs, R., Huijbrets, M., De Schryver, A., Struijs, J., and Van Zelm, R., 2013, ReCiPe 2008. PRé Consultants, CML- University of Leiden, RUN Radboud University Nijmegen Netherlands - RIVM, Bilthoven, Netherland.

[12] Ecoinvent centre, 2016, New Data in ecoinvent 3.3. The Ecoinvent Database.

[13] BSI (2006) BS EN ISO 14044:2006 Environmental management - Life cycle assessment - Requirements and guidelines. 1st ed. British Standards Institute, London.

[14] Weidema, B.P. and Wesnæs, M.S., 1996, Data quality management for life cycle inventories-an example of using data quality indicators. Journal of Cleaner Production. 4 (3), 167-174. 